year effort to digitize and network as much course reserve material as possible. The file can be accessed at http://www.lib.uconn.edu/ECR

Students are enthusiastic about the timesaving aspect of the new X-File. No longer do they have to visit the library, wait for their turn to view the materials, and then wrestle with the photocopier. Now they can get the information from the nearest networked computer.

Guided by the Reserve Services coordinator, and with the help of a programmer, student employees scanned the file of paper exams and then linked them to an academic department index from which they are accessible by course name, number, and instructor. Scanning time will be minimal in the future, since faculty now send their exams to Reserve in digital format whenever possible. Library staff are also benefiting from the switch to electronic access. The labor-intensive process of creating and maintaining a multicopy paper file has been eliminated, and repetitious charging and discharging of exams, one of the most heavily circulated materials on reserve, has been reduced. For additional information, contact Dipa Roy, Reserve Services coordinator at ecr@spirit.lib.uconn.edu or (860) 486-2307.

\section{ACRL's WESSWeb wins award}

The German newsweekly Die Zeit recently named WESSWeb, the Web service of ACRL's Western European Specialists Section, as one of 67 key sites in the emerging digital library. In a four-part article, reporter Dieter E. Zimmer identified the major issues confronting Internet users today and singled out WESSWeb for its efforts to provide easy access to information, especially electronic texts.

Zimmer's article is available on the Web at http://www4.zeit.de/bda/int/zeit/littwett/

\title{
Resources on accessible Web design and adaptive technology for libraries
}

An innovative cooperative project between the University Libraries and DO-IT (Disabilities, Opportunities, Internetworking and Technology) at the University of Washington has produced a training packet of materials on issues related to accessibility for people with disabilities to library resources. Portions of the materials were presented and enthusiastically received at ACRL's 8th National Conference in Nashville last spring.

Director of DO-I'T, Sheryl Burgstahler, comments, "We were very interested in joining with the University Libraries on this project as libraries play such an important role in providing information in our society. We are happy to report that the project sent over 300 complementary copies of the training materials to libraries across the country and that we reached over 1,500 librarians and educators through conference presentations."

The University Libraries were equally excited to join the partnership. "We enthusiastically joined DO-IT in this project," said Betty Bengtson, director of University Libraries. "As a result, our staff are more aware of the issues related to serving students and staff with disabilities. And more importintly, we are working to be better equipped to provide them services."

The training packet includes materials on accessibility issues for libraries, adaptive technology, and accessible Web design. Included are two videotape presentations on adaptive technology and accessible Web design, a presentation script that can easily be modified to one's needs, overhead transparency templates, and handout templates covering adaptive technology, accessible Web design, and library accessibility issues.

The training materials are available for purchase from DO-IT at a cost of $\$ 50.00$ U.S. for the entire package. To order, contact DO-IT by e-mail at doit@u.washington.edu, by fax at (206) $221-4171$, or by mail at 454515 th Ave. NE, Seattle, WA 98105-4527. Many of the materials are also available at DO-IT"s Web site at http:weber.u.washington.edu/doit/UA/.

Funding for the development of the materials was provided by the Telecommunications Funding Partnership and the National Science Foundation. DO-IT is directed through the College of Engineering and Computing \& Communications at the University of Washington.-Beth M. Fraser; University of Washington Libraries, bamf@u.uasbington.edu 